\title{
DOCÊNCIA EM EDUCAÇÃO FÍSICA: REFLEXÕES ACERCA DE SUA COMPLEXIDADE
}

\author{
Ricardo Rezer
}

Professor da Unochapecó e doutorando em Educação Física (PPGEF/UFSC).

\author{
Paulo Evaldo Fensterseifer \\ Professor da Unijuí e doutor em Educação Física (Unicamp).
}

\begin{abstract}
Resumo
O objetivo deste artigo é refletir acerca da complexidade da docência no campo da Educação Física (EF). Para tal, se subdivide em três momentos: a responsabilidade do entorno do processo de intervenção; a prática pedagógica no ensino superior e a formação permanente, como possibilidades importantes para resgatar a complexidade do exercício da docência em EF. Conclui-se que, uma mudança de paradigma na formação inicial, a formação permanente de caráter crítico-reflexivo e o desenvolvimento de pesquisas mais imbricadas à realidade, podem representar "focos de ruptura" possíveis de serem considerados no processo de resgate da complexidade da docência em EF.
\end{abstract}

Palavras-chave: educação física - docência - prática pedagógica

\section{Considerações iniciais...}

I niciamos por reconhecer que a Educação Física Escolar tem sido um componente passível de ser "atendido" por professores de diferentes áreas e por acadêmicos em início de formação. O critério, quando por ventura se faça necessário, é gostar de esporte, brincadeiras, ou simplesmente completar horas no plano de trabalho. Podemos inferir que este fenômeno não se aplica a outras áreas, consideradas "mais importantes", afinal ser um leitor inveterado não capacita o sujeito a assumir a disciplina de Língua Portuguesa.

$\mathrm{Na}$ verdade vivemos uma espécie de paradoxo, pois, se por um lado, não assistimos uma maior preocupação com o "fazer docente" em nossa área, porque afinal "dar aula de EF é muito fácil”, ${ }^{1}$ por outro, passamos por uma espécie de reconhecimento de que não temos

1 Ao que parece, para o imaginário social, "qualquer professor pode dar" na ausência do professor de EF. enfrentado nossos problemas "didático-metodológicos" (problema para quem?) e que por isso tem sido muito difícil "dar" aulas de EF. ${ }^{2}$

Percebendo o caráter paradoxal dessas constatações, o objetivo principal deste texto é traçar reflexões que permitam resgatar a complexidade pertinente ao campo da $\mathrm{EF}$, como possibilidade de complexificar aquilo que vem sendo, sob muitos aspectos, banalizado, barateado, simplificado: a intervenção pedagógica.

Como já afirma Guiraldelli Junior (2006), para complexificar aquilo que vem sendo banalizado, a reflexão filosófica se apresenta como uma possibilidade importante. Desta forma, se torna importante considerar que a

2 Primeiro cabe destacar que "dar aula" não é qualquer coisa que acontece em um tempo-espaço, mas fundamentalmente perseguir um objetivo pautado por determinantes próprios a instituição em que se realiza (ver mais em Fensterseifer e González, 2006). Em segundo lugar nos deparamos com depoimentos de um professor que com 30 anos de magistério, ao voltar de processo de formação doutoral, afirma, após duas semanas na escola, que não conseguiu "dar aulas de EF". 
complexificação de um fenômeno como a EF parte de um esforço filosófico. Considerar isso, em muitos casos, principia com o abandono da preguiça de pensar sobre o que fazemos e com a recusa em emitir juízos apressados.

$\mathrm{Na}$ direção de enfrentar as questões apresentadas ao longo deste texto, interpretamos a $\mathrm{EF}$ como um jogo hermenêutico de pergunta e resposta, fazendo referência ao que Berticelli (2004) traz para o campo da educação. Talvez seja necessário alargar o horizonte do perguntar, preservando a humildade do ouvir, pautando este "jogo" por um princípio ético-político de permitir a abertura para outras formas de pensar, que podem representar novos horizontes.

Resgatar a complexidade da docência significa considerar que aquilo que fazemos em uma aula de EF na escola, em uma academia ou em um laboratório de fisiologia, pode se constituir a partir de uma significativa complexidade. Não por decreto, mas sim, porque traz em sua esteira uma tradição, um nível de exigência intelectual, sensível, estética, corporal, enfim, um nível de exigência humana que pode ser bastante elevado.

É possível ilustrar as questões até aqui apresentadas, com uma breve história: em uma escola havia dois professores de EF, e um deles, por ser atleta, seguidamente ausentavase das aulas em períodos de competições. Por muitas vezes, geralmente de última hora, ele combinava com a professora de português, que o substituía nas aulas de EF. Os alunos gostavam muito quando isso acontecia e a referida professora afirmava entusiasmadamente o mesmo. Obstante a isso, os dois professores de EF da escola (o atleta e o outro) pensavam muito sobre "o que fazer" nas aulas. $\mathrm{Na}$ tentativa de enfrentar este problema, pensavam em como sair do improviso de cada aula, onde parecia que tinham de tirar um "coelho da cartola" a cada encontro. Como nesse contexto, não havia diretrizes para orientar seu trabalho, a "saída" encontrada foi construir um projeto curricular orientador. Desta forma, após o período de construção, iniciaram o processo de implantação de uma proposta para a $\mathrm{EF}$ no ensino fundamental $\left(5^{\mathrm{a}}\right.$ a $8^{\mathrm{a}}$ séries). Organizaram um cronograma de aulas, contendo um breve roteiro com os conteúdos previstos para cada encontro. Após esta nova configuração, novamente o professor atleta precisou se ausentar da escola e explicou à professora de português que o conteúdo a ser desenvolvido em aula estava em seu armário, no planejamento das turmas que teriam aula no próximo dia, na tentativa de facilitar o trabalho substitutivo da colega. Pois bem, interessante evidenciar que, no dia seguinte, logo após ler o material proposto, ela ligou imediatamente ao referido professor a fim de avisá-lo que "isso" ela não sabia fazer.

Este exemplo, aparentemente banal, nos remete à necessidade de resgatar a complexidade da docência em EF, entendendo-a realmente como algo mais do que "aplicação" de exercícios, brincadeiras ou jogos em aula (para isso, não precisaríamos cursar uma faculdade de EF, como a história anterior bem expressa). A professora de português, citada anteriormente, se sentia bem, brincando com os alunos na quadra, eles da mesma forma, mas no momento que certos conhecimentos foram requisitados, ela não os possuía. É possível então, considerar que há exigências em nosso contexto de intervenção que precisam ser melhor compreendidas.

Poderíamos pensar em diversos outros exemplos a serem utilizados como referência da complexidade do papel docente. Vejamos outro contexto: aulas de hidroginástica. Apenas recentemente os elementos constitutivos do processo de intervenção neste âmbito vêm sendo tratados no processo de formação inicial em EF. Embora, ao que parece, este processo de intervenção venha se pautando estritamente por uma preocupação técnica, é plausível considerar a possibilidade de ampliar essa compreensão. Uma aula de hidroginástica exige princípios didático-metodológicos, conhecimentos oriundos de atividades aquáticas, da ginástica, da fisiologia do exercício, dos 
princípios do treinamento desportivo, da biomecânica, entre outros. Portanto, algo mais do que "decorar" exercícios de hidroginástica para serem "aplicados" em cada aula. Ao dominar conceitos destes diferentes conhecimentos, é possível pensar em um processo de complexificação da intervenção pedagógica neste âmbito, pois o professor, ao invés da condição de "aplicador das idéias dos outros" pode alçar a condição de "professor de hidroginástica", tematizando, com intenção pedagógica, elementos pertinentes à cultura corporal de movimento, a partir do esforço de arregimentar conhecimentos de diferentes "origens".

No sentido de contextualizar e sustentar de maneira mais profícua esta argumentação inicial, subdividimos o texto em três momentos: a responsabilidade do entorno da intervenção; a prática pedagógica no ensino superior e a formação permanente como possibilidades de resgatar a complexidade do exercício da docência em EF.

\section{A responsabilização do "entorno"...}

Os argumentos anteriores sugerem que a complexidade de um processo de intervenção precisa estar imbricada com seu entorno, com outros sujeitos que compõem o contexto em questão, sob risco de assumirmos individualmente uma responsabilidade que, se é muito nossa, não é somente nossa, mas coletiva, estrutural e organizacional. Lembrando Demo (1998), tentar dar conta (sozinho) de problemas que são coletivos, trata-se de tarefa quixotesca.

No sentido de "dar conta" de nosso papel central - formação de seres humanos para o mundo -, o exercício da docência não se apresenta destituído de um entorno que se apresenta como um elemento que precisa ser levado em consideração e, por conseqüência, responsabilizado. Do contrário, conforme Fensterseifer (2006), corremos o risco de assumir, em aula, responsabilidades que extrapolam a competência do professor, "prometendo" algo que não é possível cumprir, assumindo um papel ideológico (no sentido marxiano de encobrimento da realidade). É preciso considerar que a legitimidade da docência em EF se dá, independentemente do âmbito de intervenção, na medida em que temos o que ensinar, de forma articulada em um contexto específico. Assim sendo, consideramos de extrema importância "reclamar" a responsabilidade do entorno que sustenta um processo de intervenção, como meio de ampliar as próprias possibilidades pedagógicas desse processo.

Isso significa que, para lidar com os enfrentamentos inerentes ao exercício da docência, é importante partir da constatação que não estamos sozinhos neste complexo desafio, pois em qualquer âmbito de intervenção, não "falamos" exclusivamente por nós. Para o bem e para o mal, estamos sempre em um contexto que nos autoriza (ou não) determinada proposição. Portanto, se faz necessário trazer para o debate, a responsabilização desse entorno. Da mesma forma, precisamos assumir que temos uma autonomia relativa, e não podemos fazer somente "aquilo que queremos" (por exemplo, ensinar em aulas de EF, predominantemente voleibol por "gostar" deste esporte). O próprio termo "licenciado" se apresenta nesse sentido, quando ao final de um processo formativo, recebemos a "licença" para o exercício profissional.

A figura a seguir se apresenta no sentido de ilustrar esta proposição, a partir do exercício da docência em uma universidade comunitária. Cabe lembrar que se trata de um exemplo que pode ser pensado em outros contextos, tais como a escola, entre outros.

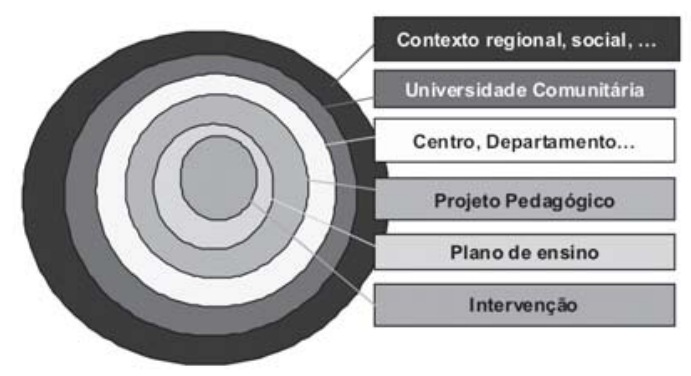

Figura 1 - A responsabilização do entorno no exercício da docência.

Fonte: construção dos autores. 
A figura permite maior clareza quando afirmamos que no momento em que um professor se depara com os alunos, não está "falando" apenas por si, mas por toda uma estrutura/conjuntura que vem a reboque no processo de intervenção. ${ }^{3}$ Por exemplo, por tratar-se de uma Instituição de Ensino Superior Comunitária, configura-se como uma universidade pública, não estatal, de gestão privada (ou seja, ao não ter um "dono", se constrói, em tese, na lógica da sustentabilidade, e não na lógica do acúmulo de capital). Portanto, é preciso considerar isso nas aulas, sendo necessário se preocupar com o que isso representa em regiões periféricas, onde a articulação de lideranças da comunidade possibilita ao ensino superior fazer parte do contexto de regiões desprivilegiadas na conjuntura do ensino superior público-estatal brasileiro (isso muito antes da explosão das universidades privadas).

Assim sendo, ao pensar no processo sobre "o que fazer" e como trabalhar nas aulas, é necessário levar em consideração este cenário, bem como, responsabilizar o contexto em questão, fomentando argumentos que resguardem esse modus operandi de uma universidade que é pública em sua origem, com tudo que isso implica. ${ }^{4}$ Isso representa que todo processo de intervenção precisa estar articulado com a estrutura (no exemplo proposto, Direção de Centro, Coordenação de Curso, Projeto Pedagógico, entre outros), tanto para manter como para modificar as possibilidades e limitações do exercício da docência em de-

3 Podemos derivar dessa compreensão um fundamento para a crítica ao chamado "professor bola" descolada da dimensão exclusivamente individual. Entendemos que o professor não pode transferir responsabilidades que são suas, para os alunos, respaldado na consagrada formulação: "o que vocês querem fazer hoje?”. Acreditamos que em uma relação pedagógica “não está tudo em jogo" (diferentemente de uma relação política).

4 Nesse caso, entre tantas outras questões, é preciso marcar a posição de como uma universidade comunitária deve tratar com o conhecimento produzido/veiculado: o conhecimento como um direito do cidadão, ou como hegemonicamente vem se transformando, em um direito do consumidor? terminado âmbito (clubes, academias, escolas municipais, estaduais, etc.).

Tais preocupações acerca da necessidade de considerar o "entorno", ao longo de um processo de escolhas pedagógicas, permite levar a discussão para o exercício da docência no ensino superior, tema abordado a seguir.

\section{A prática pedagógica no ensino superior...}

É preciso ampliar o processo de discussão e reflexão acerca da prática pedagógica no ensino superior. Percebemos que estamos atravessando um momento de forte questionamento da intervenção pedagógica no contexto escolar, nas academias, nos clubes, com a ampliação de propostas de intervenção nestes cenários. Nessa direção, também é importante criticar e apresentar propostas para a prática pedagógica no contexto do ensino superior, o que permite refletir com os futuros professores acerca das responsabilidades pedagógicas no exercício da docência, qualquer que seja o âmbito de intervenção. Práticas transformadoras no processo de formação podem proporcionar subsídios para uma prática transformadora em outros contextos, no sentido de transpor para a universidade aquilo que muitas obras propõem para outros âmbitos.

Pensar por exemplo, de que forma os professores do ensino superior, que trabalham diretamente com "modalidades esportivas", vêm se aproximando das preocupações evidenciadas neste texto, trata-se de um desafio contemporâneo. Levar isso em consideração pode promover desdobramentos significativos, fazendo com que as aulas de modalidades esportivas se apresentem como contextos específicos de um processo formativo que superem o "em si" da modalidade em questão (regras, fundamentos, sistemas, etc.).

Nessa direção, há trabalhos que se preocupam em questionar as abordagens simplificadas do ensino do esporte no contexto do ensino superior em EF, tais como os trabalhos de 
Molina Neto (1995), González (1999, 2004, 2007), Nascimento (2004), entre outros.

É possível afirmar que, mesmo com as freqüentes alterações na formação inicial em EF ocorridas nos últimos anos, conforme Nascimento (2004), as práticas pedagógicas estruturadas para o ensino dos esportes ainda se sustentam em uma abordagem tradicional do ensino. Conforme González (2004), as disciplinas esportivas não mudaram muito quanto ao tratamento do conteúdo. A aparente redução do número e carga horária de disciplinas esportivas nos currículos dos cursos de EF passa mais por uma questão de quantidade de disciplinas que por uma transformação qualitativa no entendimento do fenômeno esportivo no campo do ensino superior em EF. Assim, ao que parece, o contexto universitário carece de uma cultura acadêmica para o ensino do esporte.

É possível inferir que superar a concepção hegemônica do ensino do esporte ainda pre- sente nos contextos de formação profissional é condição sine qua non para esta superação em outros contextos. Obviamente não se trata de simples relação de causa e efeito, mas de pensar que um novo paradigma para o ensino superior pode promover significativos desdobramentos em outros âmbitos.

Do contrário, como pensar na possibilidade de "transformar" a intervenção pedagógica em diferentes contextos (em escolas, academias, etc.), se não pensarmos nestas transformações também no contexto do ensino superior? Quem desata estes "nós"? O egresso? Pensamos que a responsabilidade passa também, necessariamente, pelo contexto de formação de futuros professores.

Tomando como referência esta preocupação, Rezer (2008) apresenta sinteticamente apontamentos introdutórios para uma abordagem crítica do esporte neste âmbito:

\begin{tabular}{|l|l|}
\hline \multicolumn{1}{|c|}{ ABORDAGEM HEGEMÔNICA } & \multicolumn{1}{|c|}{ ABORDAGEM CRÍTICA } \\
\hline Aula centrada no professor e no esporte "em si". & $\begin{array}{l}\text { Aula compreendida como uma possibilidade de exercício do- } \\
\text { cente, a partir da complexidade de conteúdos presentes neste } \\
\text { contexto, sem abrir mão da responsabilidade pedagógica do } \\
\text { professor. }\end{array}$ \\
\hline Aula como lugar do A-luno (do Latim, "não luz"). & Aula como lugar do professor em processo de formação inicial. \\
\hline Aula como espaço para repassar conteúdos. & $\begin{array}{l}\text { Aula compreendida como laboratório pedagógico, de } \\
\text { experiências de docência. }\end{array}$ \\
\hline $\begin{array}{l}\text { Aula como local para o ensino de jogos, } \\
\text { "atividades", "exercícios educativos", etc. }\end{array}$ & $\begin{array}{l}\text { Compreender a aula como um espaço de aquisição de saberes } \\
\text { da docência, onde o mais importante se manifesta no sentido } \\
\text { de compreender as concepções que fundamentam as práticas } \\
\text { corporais em questão. }\end{array}$ \\
\hline Jogar na aula (praticar esportes) & $\begin{array}{l}\text { Aprender a pensar sobre o jogar, sem necessariamente, deixar de } \\
\text { jogar (praticando o exercício da docência). }\end{array}$ \\
\hline
\end{tabular}

Quadro 1 - Abordagem hegemônica e abordagem crítica para o trato com o esporte no ensino superior. Fonte: Rezer (2008).

Entendemos que todo quadro pode se tornar uma armadilha, devido a seu aparente maniqueísmo, pois parece ter a pretensão de encaixotar a realidade. Porém, podemos perceber nesta formulação, uma intenção de explicitar possibilidades concretas que venham a contribuir para um possível (re) significar do trato com o esporte no ensino superior. Partindo disso, é possível considerar possibilidades de ampliar essa discussão para outros conhecimentos pertinentes ao ensino superior em EF (ginástica, dança, entre outros). 
Cabe destacar que as considerações críticas deste texto não pretendem "resolver" problemas conjunturais construídos na trajetória histórica da EF, muito menos substituir os sujeitos na produção de possíveis soluções. Obstante a isso, ampliar a compreensão sobre estes elementos no processo de formação de professores pode permitir resgatar a complexidade da docência.

Assim, sendo possível identificar diversos desafios para o processo de formação inicial, é possível também inferir que tais desafios, se não enfrentados ao longo da formação inicial, podem promover significativos desdobramentos (problemáticos) para o exercício da docência no cotidiano do egresso. A formação permanente pode, então, se apresentar como uma "saída" plausível para enfrentar esta questão, conforme veremos a seguir.

\section{A formação permanente como possibilidade para a Constituição de "focos de ruptura"...}

Concordando com Contreras (apud MOLINA NETO et al., 2006), a tese básica da proletarização dos professores é que o trabalho docente vem sofrendo uma subtração progressiva de uma série de qualidades que conduziram os professores a uma sensível perda de controle e sentido sobre seu próprio trabalho, o que vem levando a uma gradativa perda de autonomia. Esta conjuntura vem, gradativamente, nas palavras de Tardif e Lessard (2005), ampliando o sentimento de impotência dos docentes. Pensar em "focos de ruptura" se apresenta como uma possibilidade de enfrentar a intensificação do trabalho docente que, entre outros, vem vitimando o professor sob diversos aspectos: aumento da carga horária, diminuição do tempo livre e do tempo para estudar no trabalho, entre outras significativas perdas da profissão docente.

Longe de individualizar responsabilidades, como referido anteriormente sobre a responsabilização do entorno, há responsabilidades das quais não podemos nos abster. Se compreendermos a crise contemporânea em que vivemos como um momento de tomada de decisão, avançar na reflexão sobre estas responsabilidades depende, em certa medida, dos sujeitos envolvidos, pois não há um "pai salvador" que irá nos apontar a "salvação". $\mathrm{Na}$ direção contrária do tácito afastamento da complexidade do exercício da docência que vamos sendo seduzidos a aceitar, é possível caminhar na direção de constituir "focos de ruptura" (REZER, 2003, 2006), "brechas", nas quais "pequenas" oportunidades podem representar formas de resistência ao pretenso esvaziamento da capacidade crítico-reflexiva dos docentes.

Nessa direção, "focos de ruptura" se constituem a partir de perspectivas construídas em microcontextos, de acordo com os encaminhamentos assumidos pelos envolvidos que compõem o entorno da intervenção, pautados pelo paradigma habermasiano da comunicação, alicerçados por nossa autonomia relativa, onde o melhor argumento e contra-argumento possam ser levados em consideração no processo de definição dos caminhos a serem percorridos. $^{5}$

Trazendo essa discussão para o âmbito da formação permanente, é possível contribuir com a proposição de alternativas (com todo cuidado que esta palavra exige) que permitam considerar possíveis "saídas" (mesmo que em microcontextos), que podem trazer maior segurança ao exercício da docência. ${ }^{6}$

5 O trabalho de González (2006), por exemplo, se apresenta nesta perspectiva, uma proposta de currículo para a EF escolar, construída coletivamente, tomando como recorte inicial o esporte e suas relações com o campo da educação física. Tal proposta se desenrola em um contexto específico e pode servir de inspiração e referência para novas construções específicas.

6 Precisa estar claro que não se trata de uma tentativa de individualização da responsabilidade da intervenção pedagógica, como se bastasse aos docentes se interessarem por determinadas questões, mas sim, resgatar a importância do papel docente, pois sabemos que outros condicionantes se mostram extremamente atrelados a qualquer contexto pedagógico (fatores políticos, econômicos, culturais, estruturais e outros), o que torna ainda mais desafiador pensar/fazer a educação 
Concordando com Caparroz e Bracht (2007), o docente não deve "aplicar" teoria na prática, mas sim, (re) construir (reinventar) sua prática com referência em ações e experiências anteriores, bem como, em reflexões e teorias. A apropriação de teorias precisa se dar de forma autônoma e crítica, a exemplo do que já encontramos nos periódicos especializados na área, constituindo-se em boas referências que podem ser consideradas como pontos de partida nos processos de intervenção, e não, modelos a serem "aplicados".

Nesse sentido, os achados da investigação de Molina Neto et al. (2006) permitem avançar na reflexão sobre possibilidades de lidar com esta conjuntura, a partir da perspectiva de pensar em processos de formação permanente como meio para superar as relações de dependência e resgatar, na medida do possível, possibilidades de autonomia pedagógica. Vejamos: a) inovações pedagógicas e curriculares são de difícil implantação, se desarticuladas de um projeto permanente de formação de professores; b) assim, a formação permanente se apresenta como uma possibilidade de construção de processos de mudanças de concepção e de práticas pedagógicas; c) grandes eventos de formação são geralmente destacados como importantes, mas corriqueiramente

física brasileira. Proposta interessante neste sentido tem sido desenvolvida no contexto da Unochapecó, na qual construiu-se os chamados "Encontros pedagógicos", que tem por objetivo contribuir para o processo de formação permanente a partir do estudo de temas presentes em dilemas cotidianos da prática pedagógica, fomentando o exercício da problematização, a partir dos desafios da docência neste âmbito. A cada semestre, acontecem reuniões sistemáticas e define-se a temática a ser abordada em cada semestre (quem decide isso é o grupo de professores). Em 2007.1 o tema escolhido foi "Estágio Supervisionado”, em 2007.2, “O esporte no ensino superior" e em 2008.1, "Produção do conhecimento e iniciação científica”. Em cada edição, estuda-se e discutem-se os temas em fóruns internos e, ao final de cada tempora$\mathrm{da}$, escolhe-se um convidado de outra instituição para um momento de troca de experiências, contribuindo com o processo de discussão. Podemos inferir que tal iniciativa, se não "resolve" os problemas enfrentados, vem, de acordo com o próprio grupo, promovendo desdobramentos significativos no contexto das práticas pedagógicas. perdem seu impacto quando os professores retornam ao seu trabalho, onde geralmente não encontram possibilidade de continuidade das discussões; d) a dedicação de tempo e de espaço na carga horária de trabalho para a formação permanente no contexto de trabalho é uma necessidade; e) os professores têm necessidade de falar de suas experiências pedagógicas em seu cotidiano.

Partindo dessas necessidades e das evidências de uma conjuntura complexa, é preciso analisar a possibilidade de voltar a ter escolhas, tal como expresso por Hannah Arendt (2000, 2008), resgatando a importância da capacidade de ter escolhas e deliberar, decidir, prever e escolher, condição que nos humaniza. Isso permite pensar: ainda temos escolhas? Podemos deliberar sobre o que? Quando? Até onde? Tencionar esta possibilidade humana a partir da construção de "focos de ruptura" pode significar andar na contramão da tentação da servidão voluntária em uma cada vez mais sedutora sociedade de "escravos felizes".

Essas reflexões permitem considerar algumas necessidades que um processo de intervenção exige. Partindo disso, compreendemos que, entre outras, o esforço de "ser-professor" passa por três necessidades importantes:

a) Necessidades pedagógicas: o exercício da docência em EF parte, inicialmente, de um esforço pedagógico, haja vista a necessidade de arregimentar diferentes conhecimentos para compor o processo de intervenção. Nesse sentido, é preciso considerar que suprir certas necessidades pedagógicas pode permitir uma percepção mais apurada daquilo que muitas vezes não está claro e, a possibilidade de se debruçar pedagogicamente sobre determinados fenômenos, pode permitir maiores condições de enfrentamento a dura realidade a que somos submetidos. No momento da intervenção pedagógica, é possível e necessário aproximar as diferentes "tribos"7 da EF,

7 Expressão utilizada por Lovisollo (1995). 
pois não basta ao professor, em um projeto de intervenção sério, se apresentar como sendo um fisiologista, um treinador ou mesmo como um filósofo que ensina. Ele é antes de tudo, um PROFESSOR, um educador, um pedagogo (do esporte, da saúde, enfim, de diferentes manifestações da cultura corporal de movimento) e como tal precisa se apresentar de acordo com as exigências da profissão docente em cada contexto, arregimentando e tematizando elementos do esporte, da filosofia, da fisiologia,...

b) Necessidade de (maior) domínio conceitual: resgatar a complexidade da docência passa, sem dúvida, por uma ampliação de nossa capacidade de compreensão acerca dos fenômenos que constituem nosso cotidiano. Por exemplo, dominar o conceito de equilíbrio permite maiores possibilidades de tematizar equilíbrio e identificar como nos relacionamos com a lei da gravidade, entre outras questões possíveis. Ou então, identificar o equilíbrio como parte integrante da vida, em uma eterna luta entre desequilibrar e equilibrar, presentes na caminhada ou na corrida. Isso permite considerar a possibilidade de ampliar nossa intervenção e, ao dominar tais elementos, não precisarmos, necessariamente, ser dependentes dos manuais de "atividades", ou de cursinhos de "capacitação", pois nossa prática pedagógica se pautará por uma possibilidade de autonomia que nos permite reconhecer/criar situações de equilíbrio, capacidade que não se esgota em qualquer livro de "1000 exercícios de...".

c) Necessidade de o professor afirmarse como "sujeito": ${ }^{8}$ esse processo de resgate

8 A expressão "sujeito" tem aqui o sentido de tornar possível a autonomia da ação de conhecer, mediante a resistência do sujeitar-se a outrem, tão presente no cotidiano da docência em EF: sujeitar-se a vontade dos alunos (o que vocês querem fazer hoje?), a uma desigual relação com as demais disciplinas (quando o aluno não pode participar da EF, se não se "comportar" direito ou não cumprir com da responsabilidade docente pela via do conhecimento se apresenta contrário a noção de "apagamento do sujeito", visto que, na contemporaneidade, vivemos em um momento que parece prescindir da reflexão, onde o ato de pensar por si mesmo, em tempos difíceis como o nosso, trata-se de um elemento quase revolucionário. As relações com o sistema body ou cursos de capacitação que pretensamente querem a "tudo resolver", entre outros, permitem considerar que há uma indução de afastamento tácito entre o professor e o ato de pensar. Ao transferirmos nossa responsabilidade de pensar sobre nosso papel como docente, lembrando Schopenhauer, corremos o risco de cavalgar nas idéias dos outros. Talvez, para lidar com isso, precisemos resgatar aquilo que Kant (2008) tratou como a decisão e coragem de servir-se de seu próprio entendimento sem a direção de outrem, na perspectiva de trilhar o caminho do esclarecimento, como saída do homem de sua menoridade. Isso significa sopesar a necessidade de que tenhamos maior "inteligência de navegação", participando da proposição dos rumos que seguiremos, ao invés de agir, tal como afirma Rubem Alves (2006), como remadores no interior de uma Galera que ruma sempre a um "em frente" do qual não participamos da escolha.

\section{Finalizando...}

No sentido de lidar com esses desafios, "cruzar os braços" parece não ser a melhor saída. Precisamos construir novos sentidos para o exercício da docência, complexificando o que não é simples. Resgatar a complexidade da docência no âmbito da EF passa pela ne-

\footnotetext{
suas tarefas nas aulas consideradas mais "importantes"), as condições climáticas (se chove, não tem aula), entre outras possibilidades de o professor estar subordinado a algo que lhe retira a condição de sujeito. Resgatar a autoridade do conhecimento passa por um processo de "tornar-se sujeito", de enfrentamento ao cotidiano convite à submissão e à menoridade.
} 
cessidade pedagógica de maior domínio conceitual, por um processo de afirmação como "sujeito", no qual o professor se perceba como alguém que pode produzir conhecimento e não apenas aplicar conhecimentos produzidos por outros. Nesse caso, concordando com Gamboa (2007), a teorização pedagógica deve mudar com a prática e a prática poderá se transformar com a reflexão.

Para tal esforço, considerar aspectos como: uma mudança do paradigma "aplicacionista" da formação inicial; a formação permanente assumindo um caráter críticoreflexivo, e o desenvolvimento de pesquisas mais imbricadas com a realidade em que vivemos, podem representar "focos de ruptura" possíveis no processo de aproximação entre concepção e intervenção, ${ }^{9}$ ciência e experiência, ${ }^{10}$ teoria e prática, discussões bastante presentes em diferentes propostas contemporâneas.

Alargar as possibilidades de perguntar pode ser uma saída para a aparente simplificação de uma intervenção. Porém, tal complexificação não se dá por decreto, mas sim pela possibilidade de enfrentar, pela via do conhecimento, os desafios que nossa profissão exige. Nessa direção, é possível lembrar uma passagem de Bauman (1999, p. 12),

\begin{abstract}
No formular ciertas preguntas conlleva más peligros que dejar de responder a las que ya figuran en la agenda oficial; [...]. El silencio se paga con el precio de la dura divisa del sufrimiento humano. Formular las preguntas correctas constituye la diferencia entre someterse al destino y construyrlo, entre andar a la deriva y viajar.
\end{abstract}

Finalizando, esta reflexão pretende chamar a atenção para a necessidade de novas perguntas, do "ousai pensar" do esclarecimento, mas principalmente, da necessidade

9 Tema central da IX Semana da Educação Física da UFSC, agosto de 2008, Florianópolis (SC).

10 Tema central do IV Congresso Sul-Brasileiro de Ciências do Esporte, setembro de 2008, Faxinal do Céu (PR). de continuarmos o debate a partir de estudos que possam se debruçar sobre terrenos suspeitos do exercício da docência em EF. Resgatar a complexidade do que não é simples, como pretensamente somos seduzidos a aceitar, pelas artimanhas de um processo que sufoca, minimiza e subvaloriza a importância do "ser professor" nestes tempos difíceis, passa pela reinvenção do cotidiano da sala/quadra de aula, de nossa maneira de encarar os desafios que nossa escolha profissional exige. Pensando nisso, deixamos uma última interrogação: Até que ponto as questões levantadas neste texto têm sido objeto de nossas investigações?

Enfim, se não visualizamos soluções "definitivas" para estas problematizações, podemos nos consolar com a máxima: "diante da complexidade, o melhor é ficar verdadeiramente angustiado pela dúvida, do que falsamente esclarecido". ${ }^{11}$ Assumir esta postura, porém, não nos impede de, com nossas frágeis certezas, construir coletivamente uma EF que esteja à altura dos problemas que a afligem.

\section{The teaching of physical education: reflections on its complexity}

\section{Abstract}

This article aims to reflect upon the complexity of teaching in the field of Physical Education (PE). It is divided in three parts: the responsibility of the intervention process environment; the pedagogical practice of higher education teaching; and ongoing education processes, all of which are important possibilities for reinstalling the complexity of teaching in PE. We conclude that a paradigm change in the initial stages of teacher education programs, together with ongoing education programs which stimulate criticism and reflection, and the development of research works which have a deeper link with reality may all represent breaches in the current structure which may be considered in the process of reinstalling complexity into PE teaching.

Keywords: Physical education - Teaching - Pedagogical Practice

11 Cláudio Boeira Garcia - Comunicação Oral. 
La enseñanza em educación física: reflexiones sobre su complejidad

\section{Resumen}

Este artículo pretende reflexionar sobre las complejidades de la enseñanza en el ámbito de la Educación Física (EF). Con este fin, se subdivide en tres períodos: la responsabilidad alrededor del proceso de intervención; la práctica docente en la enseñanza superior y la formación permanente, como importantes oportunidades para rescatar la complejidad del ejercicio de la enseñanza en EF. De ello se deduce que, un cambio de paradigma en la formación inicial, la formación permanente de carácter crítico reflexivo y el desarrollo de investigaciones interrelacionadas a la realidad, pueden representar "focos de perturbación" que puede ser considerado en el proceso de rescate de la complejidad de la enseñanza en EF.

Palabras-clave: Educación física - Enseñanza - Práctica Docente

\section{Referências}

ALVES, R. Filosofia da ciência: introdução ao jogo e suas regras. 11. ed. São Paulo: Edições Loyola, 2006.

ARENDT, H. A crise na educação. In: . Entre o passado e o futuro. 5. ed. São Paulo: Perspectiva, 2000.

. O labor do nosso corpo e o trabalho de nossas mãos. In: __ A condição bumana. 10. ed. Rio de Janeiro: Forense Universitária, 2008.

BAUMAN, Z. La globalización: consecuencias humanas. Argentina: Fondo de Cultura Económica, 1999.

BERTICELLI, I. A. A origem normativa da prática educacional na linguagem. Ijuí: Unijuí, 2004.

CAPARROZ, F. E.; BRACHT, V. O tempo e o lugar de uma didática da Educação Física. Revista Brasileira de Ciências do Esporte, Campinas, v. 28, n. 2, páginas 21-37, jan. 2007.

DEMO, P. Charme da exclusão social. Campinas: Autores Associados, 1998.
FENSTERSEIFER, P. E. A responsabilidade social da educação escolar (ou a "escola como instituição republicana"). In: MASS, A. K.; ALMEIDA, A. L.; ANDRADAE, E. (Orgs.). Linguagem, escrita e mundo. Ijuí: Unijuí, 2006.

FENSTERSEIFER, P. E.; GONZÁLEZ, F. J. Educação Física e cultura escolar: critérios para identificação do abandono do trabalho. In: CONGRESSO SUL BRASILEIRO DE CIÊNCIAS DO ESPORTE, 3., 2006, Santa Maria. Anais... 1 CD-ROM.

GONZÁLEZ, F. J. As disciplinas esportivas na formação superior: o que aprender e ensinar? Revista Brasileira de Ciências do Esporte, Florianópolis, v. 21, n. 1, p. 585-592, 1999.

O estudo do esporte na formação superior em Educação Física: construindo novos horizontes. Movimento, Porto Alegre, v. 10, n. 1, p. 213-229, jan./abr. 2004.

Projeto curricular e Educação Física: o esporte como conteúdo escolar. In: REZER, R. (Org.). O fenômeno esportivo: ensaios crítico-reflexivos. Chapecó: Argos, 2006.

Potencialidades e limites de uma proposta alternativa de estudo do esporte na formação superior em Educação Física: olhares de professores e acadêmicos. In: $\mathrm{CON}-$ GRESSO BRASILEIRO DE CIÊNCIAS DO ESPORTE, 15., - CONGRESSO BRASILEIRO DE CIÊNCIAS DO ESPORTE, 2., 2007, Santa Maria. Anais... 1 CD-ROM.

GAMBOA, S. S. A pesquisa como estratégia de inovação educativa: as abordagens práticas. In: _. Pesquisa em educação: métodos e epistemologias. Argos: Chapecó, 2007.

GUIRALDELLIJUNIOR, P. O que éum problema filosófico? Vídeo produzido por CHIES, F. M. São Paulo, 14 de novembro de 2006. 
KANT, I. Resposta a pergunta: que é "esclarecimento"? In: Textos seletos. 4. ed. Petrópolis: Vozes, 2008.

LOVISOLLO, H. Educação Física: a arte da mediação. Rio de Janeiro: Sprint, 1995.

MOLINA NETO, V. Uma experiência de ensino do futebol no currículo de licenciatura em Educação Física. Movimento, Porto Alegre, ano 2, n. 2, p. 29-37, 1995.

MOLINA NETO, V. et al. Os desafios da formação continuada em Educação Física: nexos com o esporte, a cultura e a sociedade. In: REZER, R. (Org.). O fenômeno esportivo: ensaios crítico-reflexivos. Chapecó: Argos, 2006.

NASCIMENTO, J. V. Metodologias de ensino dos esportes: avanços teóricos e implicações práticas. Revista Portuguesa de Ciências do Desporto, v. 4, n. 2, páginas 76-8, 2004.

REZER, R. A prática pedagógica em escolinhas de futebol/futsal: possíveis perspectivas de superação. 2003. 194 folhas. Dissertação (Mestrado em Educação Física) - Centro de Desportos do Programa de Pós-Graduação em Educação Física, Universidade Federal de Santa Catarina, Florianópolis, 2003.

O fenômeno esportivo: ponderações acerca das contradições do paradigma da "iniciação”... In: REZER, R. (Org.). O fenômeno esportivo: ensaios crítico-reflexivos. Chapecó: Argos, 2006.

-Apontamentos para o trato com o esporte na formação de professores de Educação Fisica... Chapecó, 2008. (Mimeo).

TARDIF, M.; LESSARD, C. O trabalho docente: elementos para uma teoria da docência como profissão de interações humanas. 2. ed. Petrópolis: Vozes, 2005.

Recebido em: 27/11/2008

Revisado em: 29/11/2008

Aprovado em: 08/12/2008

Endereço para correspondência

rrezer@unochapeco.edu.br 